\title{
Establishing hematopoietic stem cell transplant programs; overcoming cost through collaboration
}

\author{
Hani Al-Hashmi $\mathbb{1}^{1}$ - Ahmed Alsagheir ${ }^{2} \cdot$ Analie Estanislao $^{1} \cdot$ Jenifer Bacal $^{1} \cdot$ Ashraf Alsuhebah $^{1} \cdot$ Belal Alblowe $^{1}$. \\ Heba Raslan ${ }^{1} \cdot$ Arwa Alsaber $\mathbb{D}^{1} \cdot$ Ahmed Albahrani $^{1} \cdot$ Norah Almulhem $^{1} \cdot$ Amal Alamri $^{1} \cdot$ Khalid Alsaleh $^{3}$. \\ Amal Albeihany ${ }^{4} \cdot$ Amal Alabdulwahab $^{5} \cdot$ Mohammed Bakkar $^{6} \cdot$ Panayotis Kaloyannidis $^{1}$
}

Received: 7 September 2019 / Revised: 19 December 2019 / Accepted: 13 January 2020 / Published online: 21 January 2020

(c) The Author(s) 2020. This article is published with open access

Hematopoietic stem cell transplantation (HSCT) has dramatically evolved since the 1960s [1, 2]. It requires trained and experienced medical staffs and fully equipped centers to offer optimal care. HSCT cost data in different part of the world is ranging from 12,500 US \$ in Mexico to 549,208 US $\$$ total health care cost of myeloablative allogeneic HSCT at 1 year in the United States. However, published details on the establishment cost of HSCT programs are limited $[3,4]$. Centralizing such specialized service in few centers could negatively affect the operating cost and might result in staff burnout, long waiting lists that could lead to poor outcomes [5]. In an era of global financial constraints, innovative approaches to reach cost efficiency and optimal clinical outcomes still not readily available [6]. We sought to establish a collaborative process to expand the HSCT services in Saudi Arabia (KSA).

We used the available data on the population densities and services availabilities across KSA to guide our initiative. We have decided to start with autologous HSCT

Hani Al-Hashmi

HaniH.Hashmi@kfsh.med.sa

1 Oncology Center, Adult Hematology \& Stem Cell Transplantation Department, King Fahad Specialist Hospital, P.O. Box 15373, Dammam 31444, Saudi Arabia

2 Oncology Center, John Hopkins Aramco Healthcare, Dhahran 31311, Saudi Arabia

3 Faculty of Medicine, King Saud University, P.O Box 2925, Riyadh 11461, Saudi Arabia

4 Department of Medicine, King Fahad General Hospital, Madinah 42351, Saudi Arabia

5 Oncology Center, King Abdullah Medical City, P.O. Box 57657, Makkah 21955, Saudi Arabia

6 Oncology Department, Prince Mohamed Bin Nasser Hospital, Jizan 82943, Saudi Arabia program to build team knowledge, familiarity, and confidence with the process of HSCT as well as the economic feasibility compared to allogeneic HSCT [7]. At the beginning, experienced team of physicians, pharmacists, nurses and technicians (core team) met to discuss the need for such initiative and planed a stepwise approach to assist new centers. Four phases were planed; assessment, planning/training, site activation, and the final phase were to ensure the continuous support and improvement. We visited the clinical, pharmacy, and laboratory areas in selected centers to assess their current capabilities, which were fundamental in identifying strength, opportunities as well as the required support and training [8]. Assessment confirmed that all hospitals with chemotherapy capabilities could fulfill the minimal required criteria for establishing HSCT program as per the Worldwide Network for Blood and Marrow Transplantation recommendation [9]. We utilized this information to organize the required theoretical and hands-on training as well as logistics support. The champion in-charge of each new center identified his/her potential team members. The most important phase is planning/ training and should not be rushed, since it is considered the foundation for all future activities. Quality and administrative training were done to ensure familiarity with forms, documentation and to avoid non-conformances that could result in suboptimal quality and cost inefficiency. The new centers screened potential patients and once identified, pretransplant process, forms and consents were completed and road-maps were generated with the support of the core team and approved by the hematologist at the new center to signal site activation. This phase that would be completed by infusing the stem cells was followed by supportive care period that was characterized by full communication between the core team and the new center's team and facilitated through a WhatsApp group. The core team's involvement in the subsequent transplants was as per the new center discretion. All centers were encouraged to 
Hematopoietic stem cell transplant process timeline

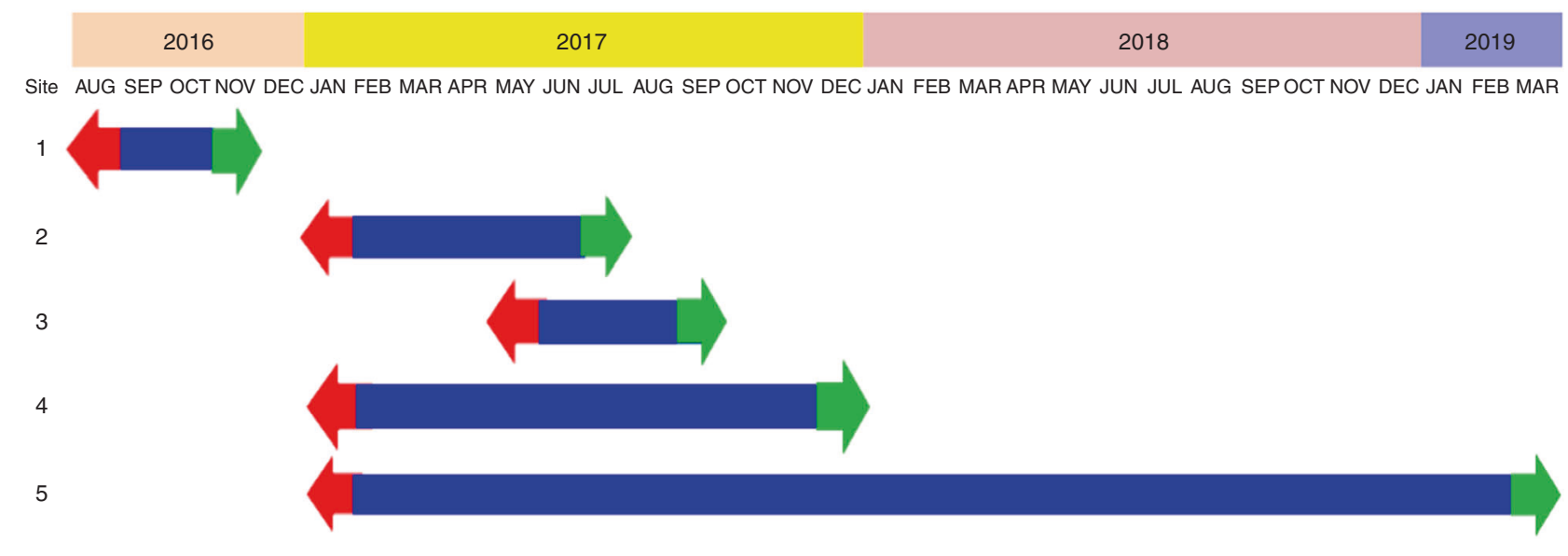

Legend:

Site visit

Plan/Training

Site activation

Fig. 1 Project time-line.

participate in an annual HSCT activity to share experiences and best practices.

Change management and stakeholder's alignment are essential for successful establishment of such program. This was very clear in center 5 were a lot of effort and time were taken to engage stakeholders and manage internal resistance (Fig. 1). Initially, we faced resistance that slowly resolved by creating a culture for the change required through aligning the patients' needs and the team ambitious goal. We focused on improving the communication platform, and celebrating success at every step. We also held a number of lessons learned sessions with the core team and the new centers to optimize the establishment process. Although, traditional communication style through regular meeting and emails are essential to discuss the details of the plan and the process, however, new technologies and applications will enhance medical communication in this era. In our project, this was fairly evident during the site activation phase since we used WhatsApp application as an additional tool to improve communication and promote faster and real-time discussion. We believe that smart solutions and technologies will greatly impact health care delivery and outcomes. This approach helped in establishing 5 new HSCT centers with average cost saving exceeded 4 million US $\$$ per center. We also introduced to our health care system an independent teams and health care providers who could contribute to future collaborations. We believe such work could be replicated to support optimal health care delivery and cost efficiency in any health care system.

Health care organizations embarking on such projects will be faced with financial constraints and limited with minimal start-up experiences. Empowering new programs though collaboration have many advantages such as overcoming multiple financial limitations, shortening the project duration and simplifying any processes benefiting from the cumulative experiences to avoid waste and non-value adding steps as well as identifying all the establishment cost saving opportunities [10]. It also gives a broader platform to apply business improvement methodologies that have been tested in different industries (manufacturing, telecommunication, aviation, etc) such as Lean Six Sigma (LSS) in the health care industry.

Acknowledgements Authors would like to thank all contributing hospitals and especially the executive administration at King Fahad Specialist Hospital in Dammam (KFSH-D) for their encouragement and support. All authors were involved in this initiative heavily at their hospitals, contributed intellectually to the manuscript and approved the final version to be published.

\section{Compliance with ethical standards}

Conflict of interest The authors declare that they have no conflict of interest.

Publisher's note Springer Nature remains neutral with regard to jurisdictional claims in published maps and institutional affiliations. 
Open Access This article is licensed under a Creative Commons Attribution 4.0 International License, which permits use, sharing, adaptation, distribution and reproduction in any medium or format, as long as you give appropriate credit to the original author(s) and the source, provide a link to the Creative Commons license, and indicate if changes were made. The images or other third party material in this article are included in the article's Creative Commons license, unless indicated otherwise in a credit line to the material. If material is not included in the article's Creative Commons license and your intended use is not permitted by statutory regulation or exceeds the permitted use, you will need to obtain permission directly from the copyright holder. To view a copy of this license, visit http://creativecommons. org/licenses/by/4.0/.

\section{References}

1. Copelan EA. Hematopoietic stem-cell transplantation. N Engl J Med. 2006;354:1813-26.

2. Singh AK, McGuirk JP. Allogeneic stem cell transplantation: a historical and scientific overview. Cancer Res. 2016;76:6445-51.

3. Jaime-Perez JC, Heredia-Salazar AC, Cantu-Rodriguez OG, Gutierrez-Aguirre H, Villarreal-Villarreal CD, Mancias-Guerra C, et al. Cost structure and clinical outcome of a stem cell transplantation program in a developing country: the experience in Northeast Mexico. Oncologist. 2015;20:386-92.
4. Broder MS, Quock TP, Chang E, Reddy SR, Agarwal-Hashmi R, Arai S, et al. The cost of hematopoietic stem-cell transplantation in the United States. Am Health Drug Benefits. 2017;10: 366-74.

5. Franco MMR, Rodriguez EL. Importance of nongovernmental organizations for the establishment of a successful hematopoietic stem-cell transplantation program in a developing country. J Glob Oncol. 2018;4:1-8. https://doi.org/10.1200/JGO.17.00091

6. Das K, Khanna T, Agrawal N. Establishing hematopoietic stem cell transplant unit in resource limited setting: a critical analysis of indian council of medical research 2017 guidelines. J Transpl. 2018;2018:4. 12923074.

7. Chaudhri NA, Aljurf M, Almohareb FI, Alzahrani HA, Bashir Q, Savani B, et al. Establishing an autologous versus allogeneic hematopoietic cell transplant program in nations with emerging economies. Hematol Oncol Stem Cell Ther. 2017;10:173-7.

8. Casebeer A. Application of SWOT analysis. Br J Hosp Med. 1993;49:430-1.

9. Pasquini MC, Srivastava A, Ahmed SO, Aljurf M, Atsuta Y, Doleysh C, et al. Worldwide network for blood and marrow transplantation recommendations for establishing a hematopoietic cell transplantation program, Part I: Minimum requirements and beyond. Biol Blood Marrow Transpl. 2019;25: 2322-9. In-Press

10. Gomez-Almaguer D. The simplification of the SCT procedures in developing countries has resulted in cost-lowering and availability to more patients. Int J Hematol. 2002;76 Suppl 1:380-2. 